\title{
Experimental Study \& Optimization of Machining Parameters in Turning of AISI 1040 Steel with Micro- grooved WC Cutting Tools
}

\author{
P. N. L. Pavani ${ }^{1, *}$, C. L. V. R. S. V. Prasad ${ }^{1}$, and K. Ramji ${ }^{2}$ \\ 1 Department of Mechanical Engineering, GMR Institute of Technology, Rajam, Andhra Pradesh, India \\ 2 Department of Mechanical Engineering, Andhra University, Visakhapatnam, Andhra Pradesh, India \\ *E-mail: pavani.pnl@gmrit.org(Corresponding author)
}

\begin{abstract}
In dry turning, control over chip formation and the need for the automated machining lead to an advancement in cutting tools. Such concern towards chip breakability is necessary in reducing tool wear, tool tip temperatures and surface roughness of workpiece material. The present study proposes a new development in the traditionally available cutting tools, which acts like a chip breaker. A series of micro-grooves are machined on the rake face of Tungsten carbide (WC) cutting tools using sinker Electric Discharge Machine (EDM). These micro-grooved tools are used to dissolve long continuous chips and heat from the cutting zone in the dry machining of AISI 1040 steel. The results of micro-grooved cutting tools have shown improvement in reducing the tool tip temperatures and surface roughness compared to the conventional cutting tools. The consolidated chip flow phenomenon of plain WC tools is used to decide the location of micro-grooves on the tool rake face. A Taguchi orthogonal array is used to design an experimental layout with minimum number of repetitions in the experiments. Signal-tonoise ratios and ANOVA is used to understand and identify the significant factors \& their level among the input variables on responses.From the results, it is identified that the cutting speed is the most influencing parameter for tool tip temperature at level 1 (i.e.112 $\mathrm{m} / \mathrm{min}$ ) and surface roughness at level $5($ i.e. $720 \mathrm{~m} / \mathrm{min}$ ).
\end{abstract}

Keywords: Dry machining, rake face, sinker EDM, micro-grooves, signal-to-noise ratios and ANOVA.

ENGINEERING JOURNAL Volume 21 Issue 4

Received 6 October 2016

Accepted 27 December 2016

Published 31 July 2017

Online at http://www.engj.org/

DOI:10.4186/ej.2017.21.4.155 


\section{Introduction}

Dry, semi dry and MQL (Green Machining) techniques have already proven that they can reduce the lubrication costs approximately by $15 \%$. These techniques can also be used to decrease the environmental pollution compared to the conventional methods. According to Ghosh and Mallik(1985) natural roughness depends on tool geometry, built up edge formation, chips and cutting parameters especially on cutting speed [1]. In turning, chip formation and its analysis is necessary because the formation of continuous or discontinuous chips may lead to high cutting forces, heat generation and poor surface quality. Asthakov et al. (1997) presented a classification of chip structures based on mechanics of its formation. Generally chips are classified into various types based on its post process analysis. Authors have proposed a new technique to classify the chips based on chip structure, chip stress and strains as a result of chip formation dynamics. This technique can be used to predict the chip breakability [2]. Miroslav Neslusan et al. (2011) analyzed the chip formation in machining of annealed and hardened roll bearing steel through acoustic emission technique. As per the results, it has been identified that the segmented chips are formed while turning hardened steel and its frequency was found to be very high [3]. Sutter et al.(1997) designed a new device to study the cutting process and chip formation under high speed machining conditions. The device enables to investigate orthogonal cutting process at various ranges of speeds starting from $1 \mathrm{~m} / \mathrm{sec}$ to $100 \mathrm{~m} / \mathrm{sec}$. During machining it was observed that both continuous and discontinuous chips are formed later they segregated into smooth, wavy and segmented chips [4]. Kundan et al. (2014) have done a literature survey on the effect of rake angles and material properties of chip formation in turning of mild steel with HSS tool bits. It has been found that the cutting force decreases with an increase in the rake angles where as it increases when there is an increase in the cutting speed. Whereas the tool chip friction can be increased with an increase in the negative rake angle and cutting speed [5]. Senthil kumar et al. (2014) analyzed the chip morphology in the machining of super duplex stainless steel under gas cooled environmental condition. During analysis of chips it was found that the sharp edges of chips are produced at the optimized conditions and are reduced compared to dry and wet machining conditions. Under gas cooled conditions, the chips are of discontinuous type and also in white silver color [6]. Jin Xie et al.(2012) studied chip topography in dry turning of titanium alloy with traditional plate, orthogonal micro-grooved and diagonal micro-grooved tools. The analysis of experimental results of these tools has shown that the cutting sparks, tool wear, 3D chip size and chip saw-tooth size were low in case of micro-grooved cutting tools when compared to the traditional plate tool. It is also confirmed that the diagonal micro-grooved tools are suitable and stable in dry cutting of titanium alloys. These tools can decrease shear angle by $24.3 \%$ compared to orthogonal micro-grooved cutting tools [7]. Kumaragurubaran et al. analyzed the effect of various turning parameters on its performance in machining of EN-9 steel material. The Taguchi DOE technique was applied with an L9 orthogonal array. The results have shown that the metal removal rate is mostly influenced by feed rate [8]. A brief summary on literature study of various optimization techniques and the effect of process parameters is presented in Table 1.

\section{Micro-grooves Machining on the Rake Face Using Sinker EDM}

During turning experiments on AISI 1040 steel using plain tungsten carbide cutting tools, it has been identified that the spread over zone crater wear is about $1100 \mu \mathrm{m} \& 700 \mu \mathrm{m}$ under low and high machining conditions as shown in Table 2 [1]. Whereas the chip travel length is increased by 14.5\% under medium machining conditions compared to other machining conditions. Further, it is also observed that the average area of crater wear is of about $2.25 \mathrm{~mm}^{2}$. Analysis of rake face of plain tungsten carbide cutting tools revealed that the consolidated wear zones on the rake face are located at a distance of 200-500 $\mu \mathrm{m}$ from the side and end cutting edges and $1400 \mu \mathrm{m}$ from nose [2]. So, it is planned to machine micro-grooves within the specified wear zones on the rake face using sinker EDM as shown in Fig. 1. Electronica make smart ZNC machine with Pure Copper electrodes of dimensions $80 \mathrm{X} 20 \mathrm{X} 20 \mathrm{~mm}$ have been used to machine grooves on the plain Tungsten carbide cutting tools. A total of 28 cutting tools with micro-grooves along the cutting edge have been used for experimentation on lathe machine as shown in Fig. 1. 


\section{Methodology Used \& Experimentation with Micro-grooved Cutting Tools}

\subsection{Methodology Used}

The methodology used in this study is presented in Fig. 2. is used to conduct experiments with microgrooved cutting tools. 32 experiments with $\mathrm{OA}^{32}\left(2^{31}\right)$ orthogonal array are designed using Taguchi design methodology. Cutting speed, feed and depth of cut are taken as factors at five different levels to design the experimental layout. Besides these factors, interactions between the factors are also considered. As there is no standard Taguchi orthogonal array is designed that best fits the given number of factors and their levels. So, the required array is designed by taking an existing array and reducing it to the required type of model using multi-level column criterion and dummy level techniques. This approach is used to reduce the number of experiments from $2^{31}$ to 32 . Later these 32 experiments are grouped into three categories viz., low, medium and high machining conditions as shown in Table 3.

\subsection{Experimentation with Micro-grooved Cutting Tools}

Out of these 32 experiments, 28 experiments are conducted on AISI 1040 steel using micro-grooved plain tungsten carbide cutting tools. Dry machining is done under all machining conditions and after each test, tool tip temperatures and surface roughness values are measured using a non-contact type thermometer and surface roughness tester (Mitutoyo SJ-201) as shown in Fig. 3. The non-contact type thermometer is calibrated first using a thermocouple setup and the average error is about $0.2 \%$. The tabulated values are presented in Table 4.

During the experimentation with micro-grooves cutting tools, it is observed that the grooves on the rake face of the tool acts as a chip breaker which also avoids the formation of long chips. In turn, it helps in decreasing the tool wear and an increase in its life. The photographs of the chips formed during the experimentation and SEM images of the WC cutting tool bits are presented in Figs. 4 \& 5. The plain microgrooved Tungsten carbide cutting tools used for conducting the planned 32 experiments are observed under scanning electron microscopy (SEM). The SEM images show that micro-grooves machined on the rake face avoids the formation of excessive tool wear and long continuous chips as the grooves acts as a chip breaker. Few SEM images of L6 and L9 machining conditions are depicted in Figs. 4 \& 5, i.e. at cutting speeds $180,280 \mathrm{~m} / \mathrm{min}$, feeds $0.045,0.063 \mathrm{~mm} / \mathrm{rev}$ and depth of cuts $2,0.5 \mathrm{~mm}$, respectively.The chips formed during machining are of continuous type up to some time for some of the machining conditions because of constant stress, strain and temperature gradients. Later these continuous chips are broken into small chips as the micro-grooves on the rake face of the cutting tools acts as chip breakers. However, it is identified that the high speed machining conditions are suitable in terms of getting good surface finish even though the tool wear is comparatively high.

In general, small, discontinuous chips are formed when machining is done at low cutting speeds. Whenever the speed is increased, there may be a chance of formation of long continuous chips. So, these micro-grooved cutting tools can be preferred in those situations where high speed machining is needed. Figure 5, SEM images show that the micro-grooves machined on the rake face performed two functions; as a chip breaker and the formation of good surface finish even at high cutting speeds.

Table 1. Some more literature review.

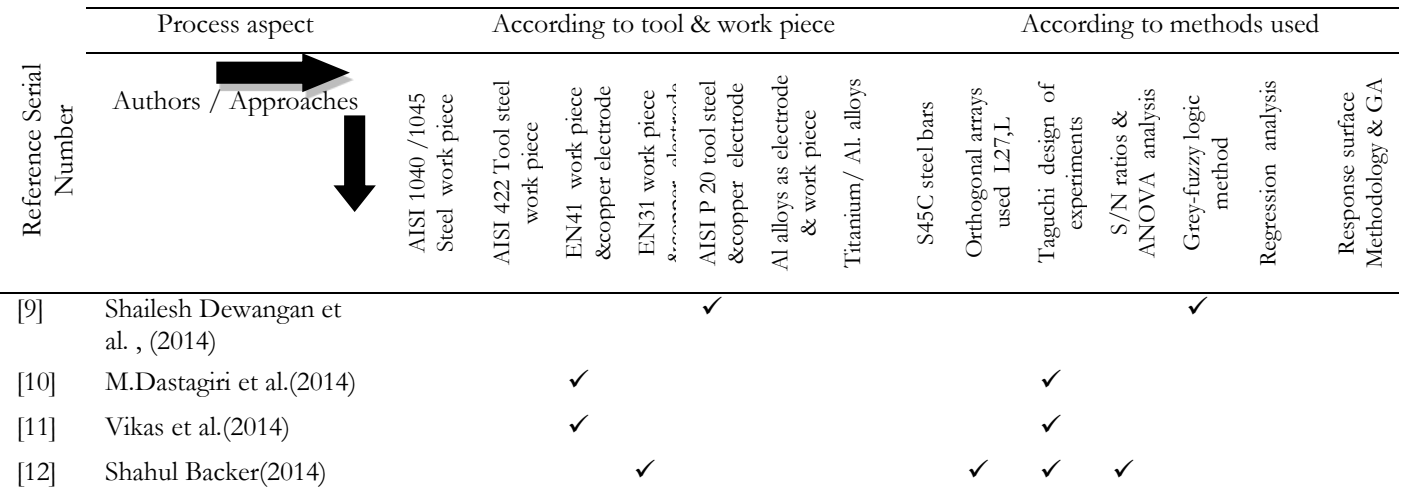




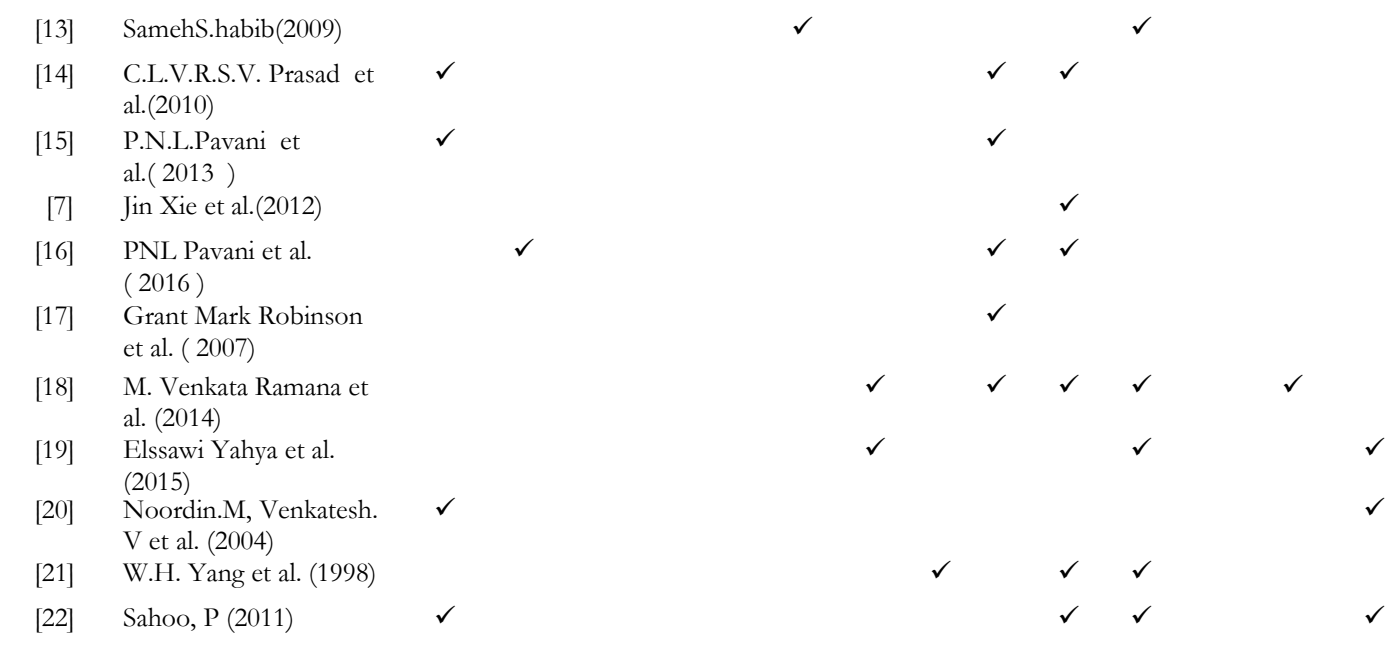

Fig. 1. Experimental setup used for machining of Micro-grooves on the rake face of WC cutting tools.

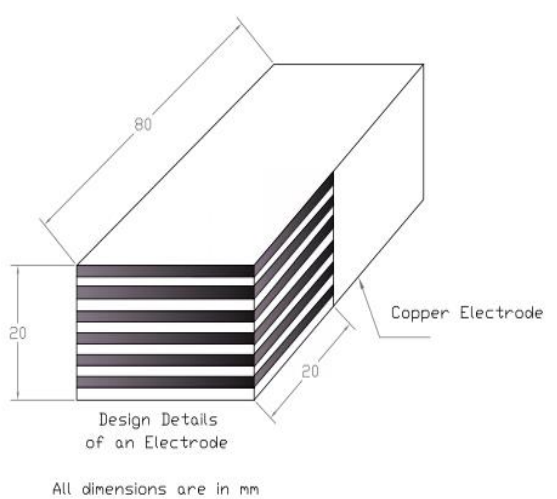

a. Details of the pure copper electrode used for machining Micro-grooves on the rake face of WC cutting tools

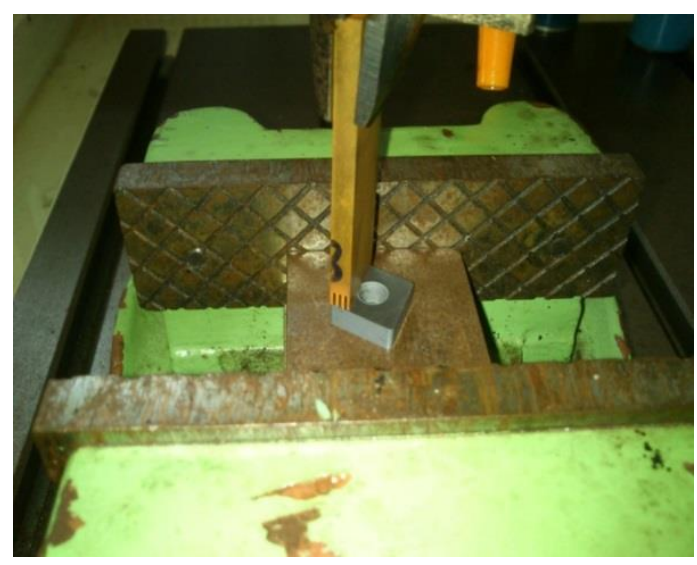

c. Setup of electrode and workpiece used for the experimentation

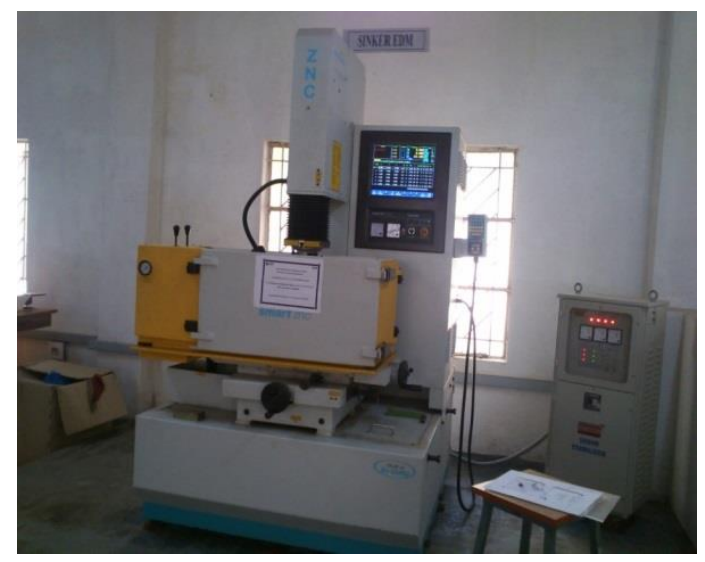

b. Electric discharge machine used for machining of Micro-grooves on the rake face of WC cutting tools

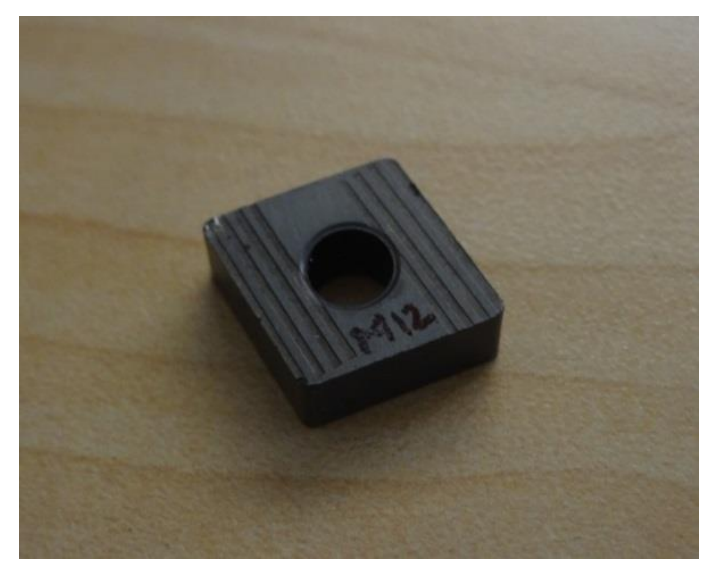

d. WC cutting tool used for doing M12 machining condition

Table 2. Combination of machining parameters and their levels considered for experimentation. 


\begin{tabular}{llll}
\hline $\begin{array}{c}\text { Levels/ } \\
\text { Factors }\end{array}$ & $\begin{array}{c}\text { Cutting } \\
\text { speed } \\
(\mathrm{m} / \mathrm{min})\end{array}$ & $\begin{array}{c}\text { Feed } \\
(\mathrm{mm} / \mathrm{rev})\end{array}$ & $\begin{array}{c}\text { Depth of } \\
\text { cut } \\
(\mathrm{mm})\end{array}$ \\
\hline 1 & 112 & 0.045 & 0.5 \\
2 & 180 & 0.063 & 1 \\
3 & 210 & 0.09 & 1.5 \\
4 & 450 & 0.125 & 2 \\
5 & 710 & 0.16 & 2.5 \\
\hline
\end{tabular}

Table 3. Dry machining conditions- low, medium and high used for experimentation.

\begin{tabular}{ccccc}
\hline Exp.No & Code & $\begin{array}{c}\text { Cutting } \\
\text { speed } \\
(\mathrm{m} / \mathrm{min})\end{array}$ & $\begin{array}{c}\text { Feed } \\
(\mathrm{mm} / \mathrm{rev})\end{array}$ & $\begin{array}{c}\text { Depth of } \\
\text { cut } \\
(\mathrm{mm})\end{array}$ \\
\hline Low Machining Conditions & & & \\
\hline 1 & $\mathrm{~L}(1,32)$ & 112 & 0.045 & 0.5 \\
2 & $\mathrm{~L}(3,30)$ & 112 & 0.05 & 1.5 \\
3 & $\mathrm{~L}(2,31)$ & 112 & 0.09 & 0.5 \\
4 & $\mathrm{~L}(4,29)$ & 112 & 0.09 & 1.5 \\
5 & L25 & 180 & 0.063 & 1 \\
6 & $\mathrm{~L} 6$ & 180 & 0.063 & 2 \\
7 & L27 & 180 & 0.063 & 2.5 \\
8 & L26 & 180 & 0.125 & 1 \\
\hline Medium Machining Conditions & & & \\
\hline 9 & M5 & 180 & 0.125 & 2.5 \\
10 & M7 & 180 & 0.16 & 1 \\
11 & M28 & 180 & 0.16 & 2 \\
12 & M8 & 180 & 0.063 & 1 \\
13 & M(9,24) & 280 & 0.045 & 0.5 \\
14 & M(11,22) & 280 & 0.045 & 1.5 \\
15 & M(10,21) & 280 & 0.09 & 0.5 \\
16 & M(12,23) & 280 & 0.09 & 1.5 \\
\hline High Machining Conditions & & & \\
\hline 17 & H16 & 450 & 0.063 & 1 \\
18 & H14 & 450 & 0.063 & 2.5 \\
19 & H13 & 450 & 0.125 & 2 \\
20 & H15 & 450 & 0.16 & 1 \\
21 & H17 & 710 & 0.063 & 1 \\
22 & H19 & 710 & 0.063 & 2 \\
23 & H18 & 710 & 0.09 & 1.5 \\
24 & H20 & 710 & 0.16 & 2.5 \\
\hline \multicolumn{7}{c}{ M } & & & \\
\hline
\end{tabular}

\section{Optimization of Experimental Results Using ANOVA Technique}

In this study, Signal to noise ratios are calculated to identify the most influencing parameter among the selected input parameters. Furthermore ANOVA is also carried out for all response variables to know the level of that particular influencing factor (among the input variables cutting speed, feed and depth of cut) which significantly affects the performance characteristics of the micro-grooved cutting tools. For the present analysis, to calculate the $\mathrm{S} / \mathrm{N}$ ratios for all response variables, a smaller-the-better criterion is used. This characteristic is used because minimum tool tip temperature and surface roughness values are preferable for better performance of the micro-grooved WC cutting tools.

$\mathrm{S} / \mathrm{N}$ ratios for tool tip temperature are calculated as per the following eq $\{1\}$ and the values are tabulated in Table 4. 


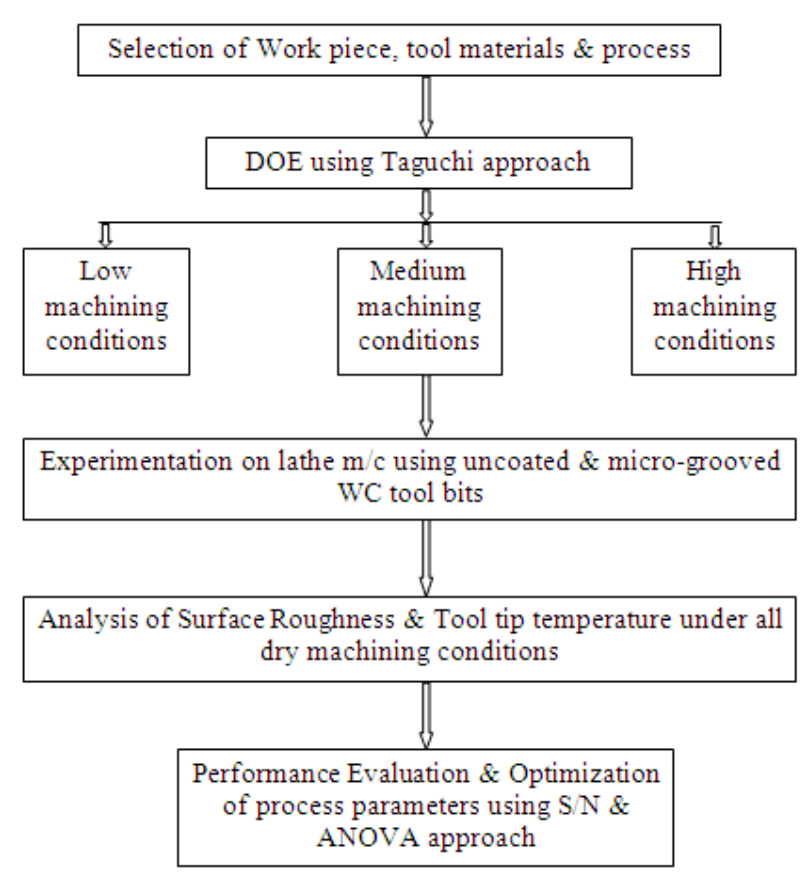

Fig. 2. Experimental methodology used for the present study.

$$
\frac{S}{N}=-10 * \log \left\{\frac{\sum(y)^{2}}{n}\right\}
$$

From the results shown in Table 4, it is identified that the tool tip temperature is mostly influenced by the input variable cutting speed. Furthermore the ANOVA results (Table 5) shows that the cutting speed value at level 1 (i.e. $112 \mathrm{~m} / \mathrm{min}$ ) is a preferable one among all range of values for tool tip temperature. Figure 6 represents the main effect plots for tool tip temperature with respect to the input variables. These plots are helpful to examine differences between level means for one or more factors which may affect the response differently.From the graphs it is identified that minimum tool tip temperature is found at medium cutting speed, low feed and depth of cut conditions.

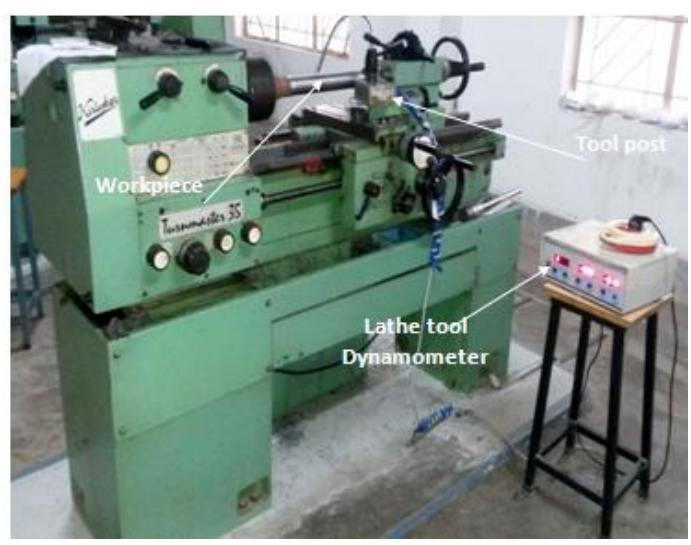

a. Experimental setup

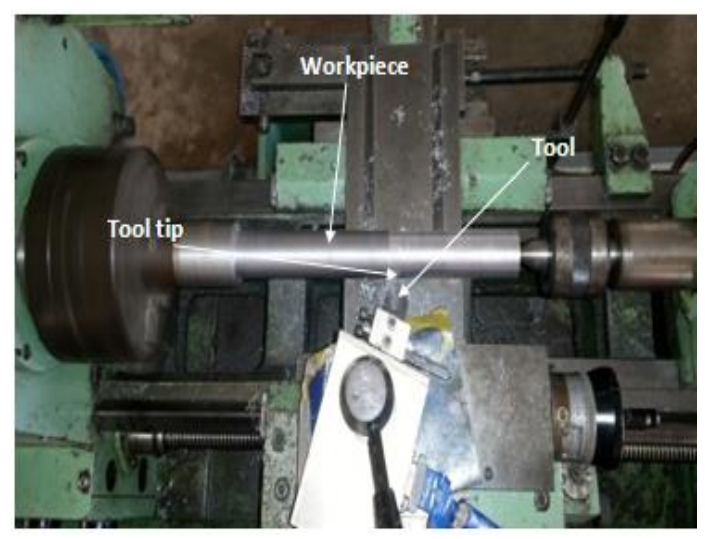

b. Close view of the experimental setup 


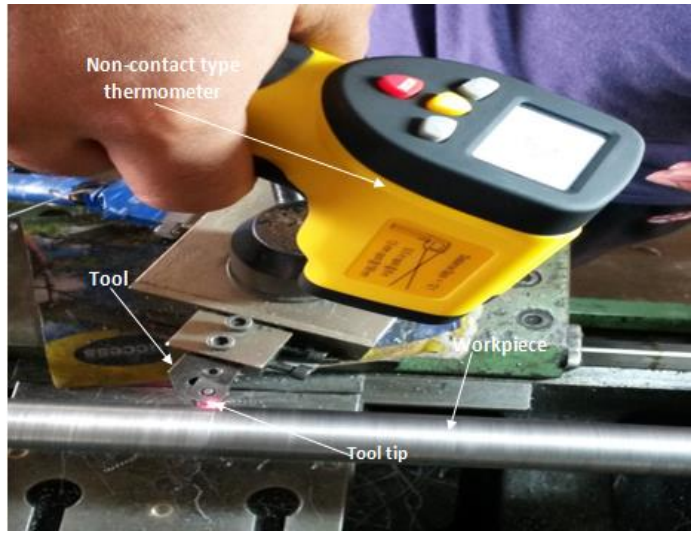

c. Temperature measurement

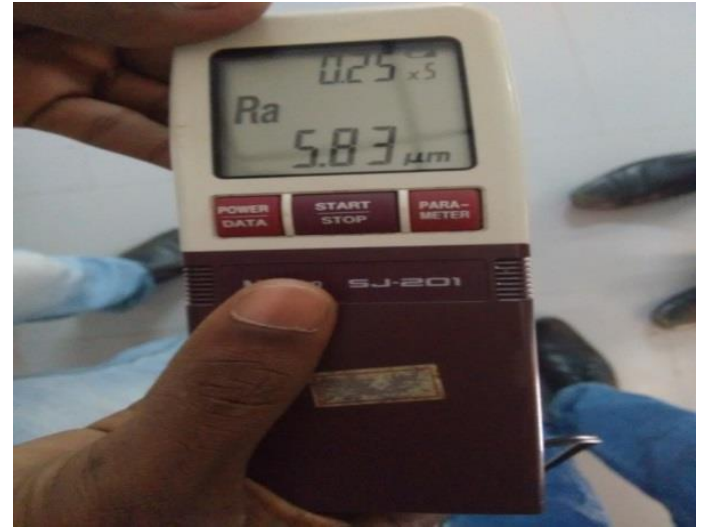

d. Surface roughness tester used

Fig. 3. Experimentation on Lathe machine under low, medium and high machining conditions using micro-grooved WC cutting tools.

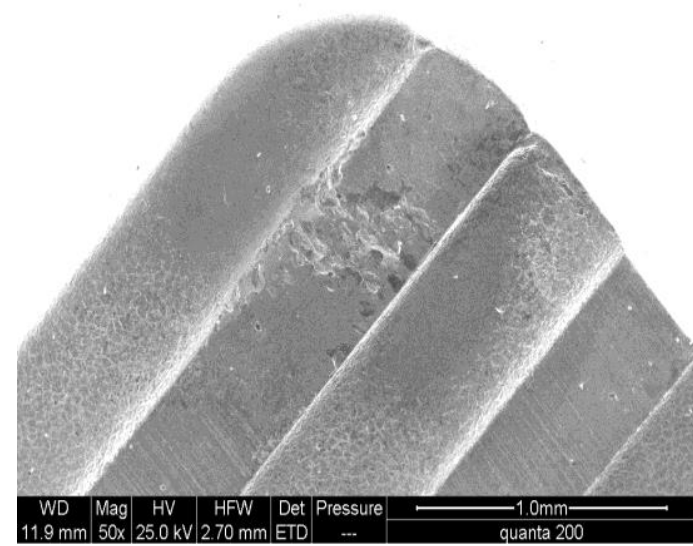

SEM image of the WC cutting tool at M9 machining condition

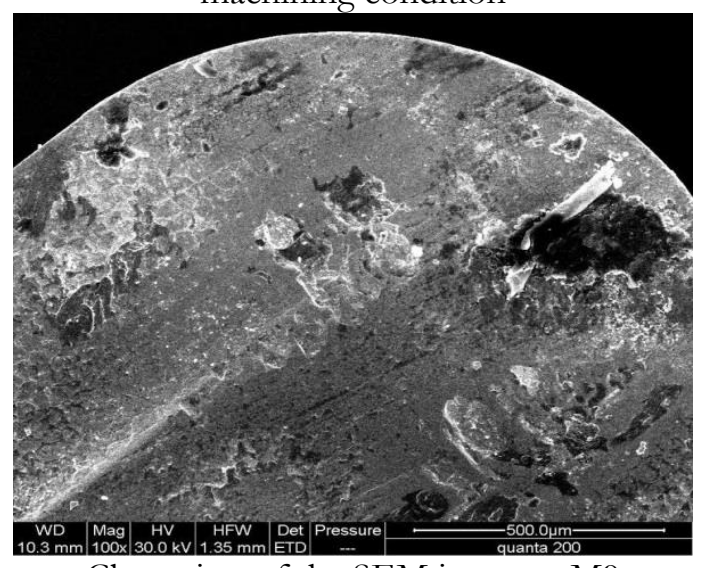

Close view of the SEM image at M9 machining condition

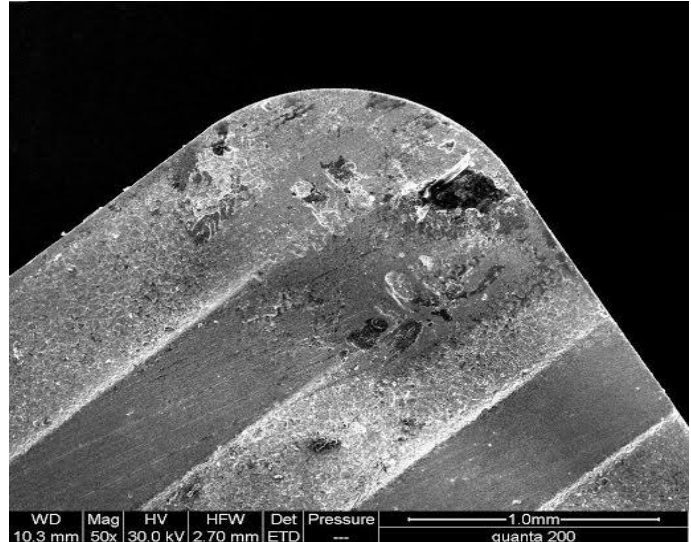

SEM image of the WC cutting tool at L6 machining condition

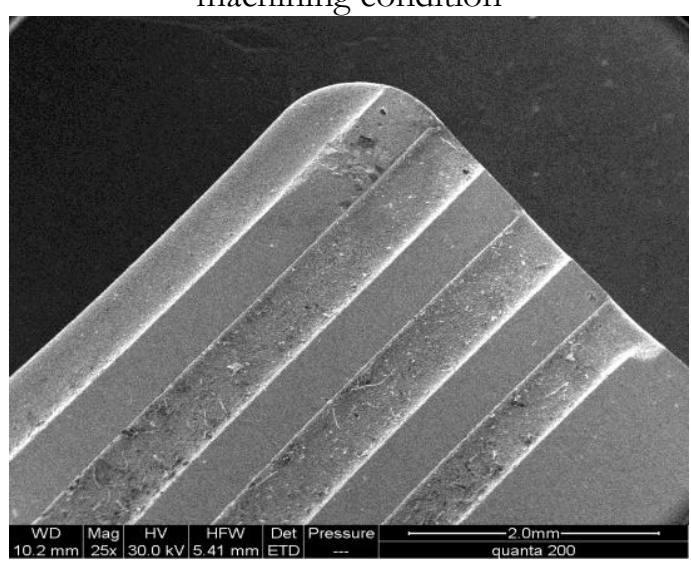

Close view of the SEM image at L6 machining condition

Fig. 4. SEM images of the WC cutting tools at various machining conditions. 
Table 4. Experimental values- tool tip temperatures and surface roughness values for all dry machining conditions.

\begin{tabular}{cccccc}
\hline $\begin{array}{c}\text { Exp. } \\
\text { No }\end{array}$ & $\begin{array}{c}\text { Cutting } \\
\text { speed } \\
(\mathbf{m} / \text { min) }\end{array}$ & $\begin{array}{c}\text { Feed } \\
(\mathbf{m m} / \mathbf{r e v})\end{array}$ & $\begin{array}{c}\text { Depth of cut } \\
(\mathbf{m m})\end{array}$ & $\begin{array}{c}\text { Tool } \\
\text { Tip } \\
\text { Temp. } \\
\left({ }^{\mathbf{C}} \mathbf{)}\right.\end{array}$ & $\begin{array}{c}\text { Avg. } \\
\text { Surface } \\
\text { Roughnes } \\
\mathbf{s} \\
(\boldsymbol{\mu m})\end{array}$ \\
\hline \multicolumn{2}{l}{ Low Machining Conditions } & & & & \\
L(1,32) & 112 & 0.045 & 0.5 & 33.5 & 4.1 \\
L(2,31) & 112 & 0.09 & 0.5 & 35.2 & 4.17 \\
L(3,30) & 112 & 0.05 & 1.5 & 33.8 & 3.35 \\
L(4,29) & 112 & 0.09 & 1.5 & 34 & 3.98 \\
L6 & 180 & 0.063 & 2 & 35.6 & 4.33 \\
L25 & 180 & 0.063 & 1 & 34.6 & 2.99 \\
L26 & 180 & 0.125 & 1 & 37.2 & 4.17 \\
L27 & 180 & 0.063 & 2.5 & 39 & 4.48 \\
\hline Medium Machining Conditions & & & & \\
M5 & 180 & 0.125 & 2.5 & 40.8 & 9.06 \\
M7 & 180 & 0.16 & 1 & 35.8 & 7.52 \\
M8 & 180 & 0.063 & 1 & 33.2 & 4 \\
M(9,24) & 280 & 0.045 & 0.5 & 32.9 & 8.23 \\
M(10,21) & 280 & 0.09 & 0.5 & 34.4 & 4.15 \\
M(11,22) & 280 & 0.045 & 1.5 & 34.9 & 3.8 \\
M(12,23) & 280 & 0.09 & 1.5 & 34.1 & 4.52 \\
M28 & 180 & 0.16 & 2 & 35.8 & 8.9 \\
\hline High Machining Conditions & & & & \\
H13 & 450 & 0.125 & 2 & 44.9 & 7.93 \\
H14 & 450 & 0.063 & 2.5 & 48.3 & 5.54 \\
H15 & 450 & 0.16 & 1 & 40.1 & 6.84 \\
H16 & 450 & 0.063 & 1 & 35.6 & 4.53 \\
H17 & 710 & 0.063 & 1 & 38 & 2.08 \\
H18 & 710 & 0.09 & 1.5 & 38 & 3.11 \\
H19 & 710 & 0.063 & 2 & 44.2 & 1.57 \\
H20 & 710 & 0.16 & 2.5 & 39.1 & 1.93 \\
\hline
\end{tabular}

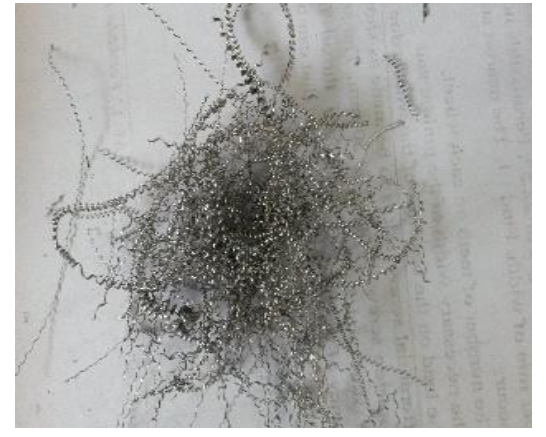

$\mathrm{s}=112 \mathrm{~mm} / \mathrm{min}$, $\mathrm{f}=0.045 \mathrm{~mm} / \mathrm{rev} \& \mathrm{~d}=0.5 \mathrm{~mm}$

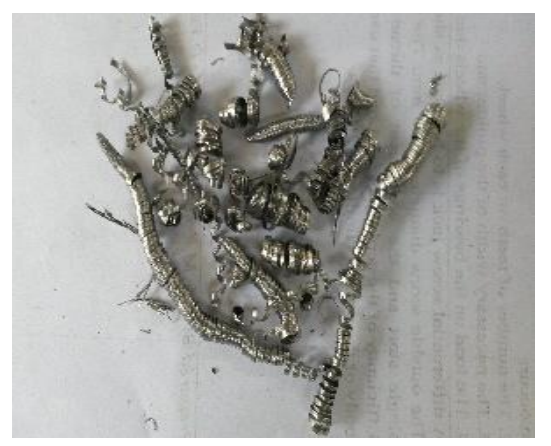

$\mathrm{s}=112 \mathrm{~mm} / \mathrm{min}$, $\mathrm{f}=0.09 \mathrm{~mm} / \mathrm{rev} \& \mathrm{~d}=0.5 \mathrm{~mm}$ 


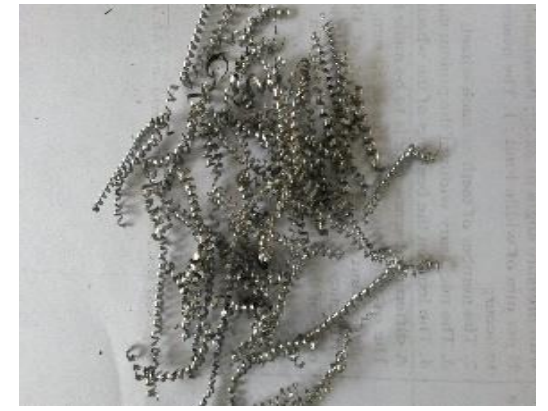

$\mathrm{s}=112 \mathrm{~mm} / \mathrm{min}$, $\mathrm{f}=0.05 \mathrm{~mm} / \mathrm{rev} \& \mathrm{~d}=1.5 \mathrm{~mm}$

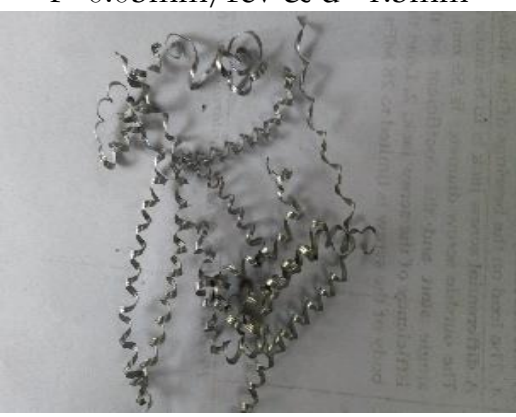

$\mathrm{s}=180 \mathrm{~mm} / \mathrm{min}$,

$\mathrm{f}=0.063 \mathrm{~mm} / \mathrm{rev} \& \mathrm{~d}=2 \mathrm{~mm}$

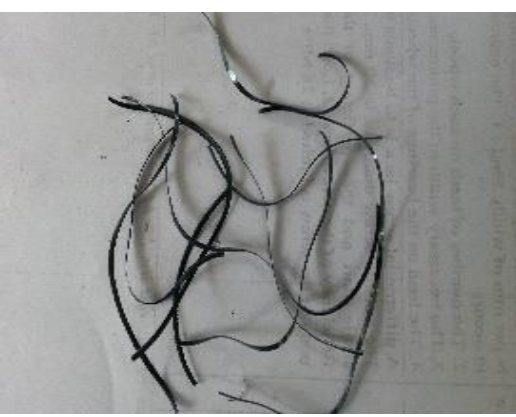

$\mathrm{s}=180 \mathrm{~mm} / \mathrm{min}$, $\mathrm{f}=0.063 \mathrm{~mm} / \mathrm{rev} \& \mathrm{~d}=1 \mathrm{~mm}$

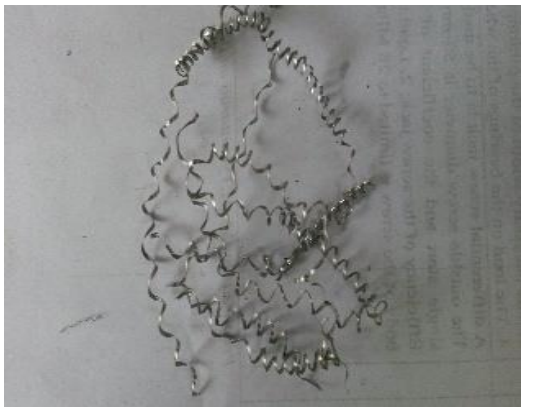

$\mathrm{s}=180 \mathrm{~mm} / \mathrm{min}$, $\mathrm{f}=0.063 \mathrm{~mm} / \mathrm{rev} \& \mathrm{~d}=1 \mathrm{~mm}$

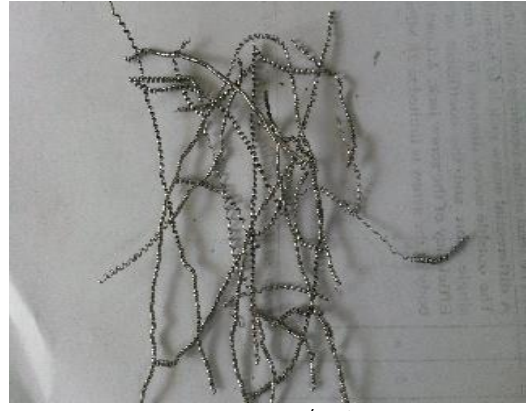

$\mathrm{s}=112 \mathrm{~mm} / \mathrm{min}$, $\mathrm{f}=0.09 \mathrm{~mm} / \mathrm{rev} \& \mathrm{~d}=1.5 \mathrm{~mm}$

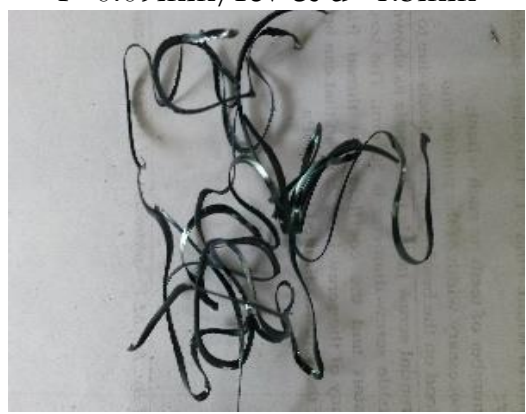

$\mathrm{s}=180 \mathrm{~mm} / \mathrm{min}$, $\mathrm{f}=0.063 \mathrm{~mm} / \mathrm{rev} \& \mathrm{~d}=1 \mathrm{~mm}$

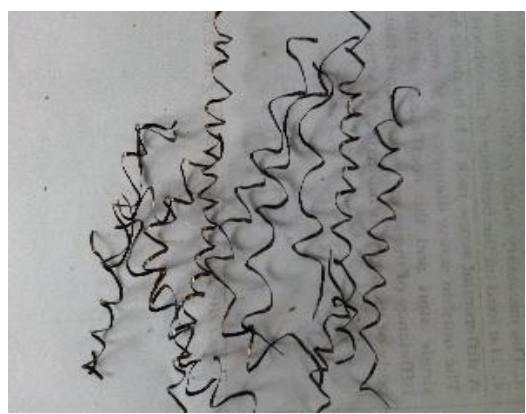

$\mathrm{s}=180 \mathrm{~mm} / \mathrm{min}$,

$\mathrm{f}=0.063 \mathrm{~mm} / \mathrm{rev} \& \mathrm{~d}=2.5 \mathrm{~mm}$

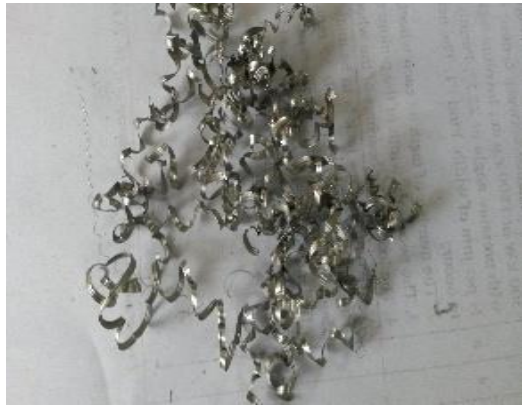

$\mathrm{s}=180 \mathrm{~mm} / \mathrm{min}$, $\mathrm{f}=0.063 \mathrm{~mm} / \mathrm{rev} \& \mathrm{~d}=1 \mathrm{~mm}$ 


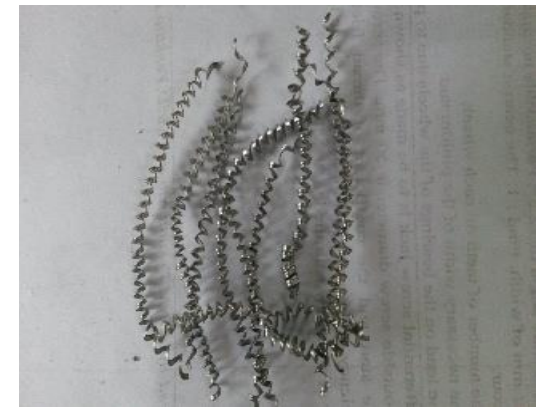

$\mathrm{s}=180 \mathrm{~mm} / \mathrm{min}$, $\mathrm{f}=0.063 \mathrm{~mm} / \mathrm{rev} \& \mathrm{~d}=1 \mathrm{~mm}$

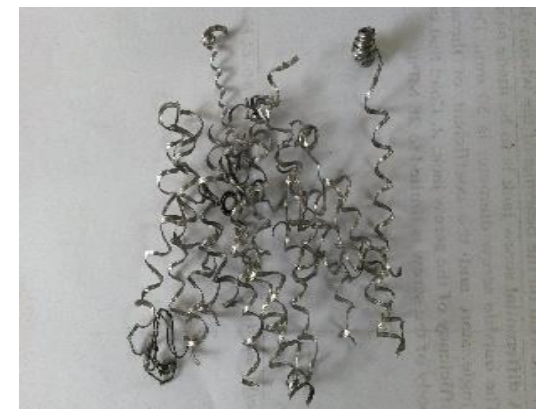

$\mathrm{s}=280 \mathrm{~mm} / \mathrm{min}$, $\mathrm{f}=0.09 \mathrm{~mm} / \mathrm{rev} \& \mathrm{~d}=0.5 \mathrm{~mm}$

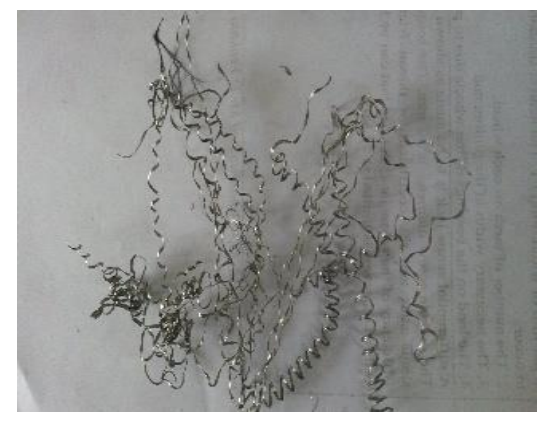

$\mathrm{s}=280 \mathrm{~mm} / \mathrm{min}$, $\mathrm{f}=0.09 \mathrm{~mm} / \mathrm{rev} \& \mathrm{~d}=1.5 \mathrm{~mm}$

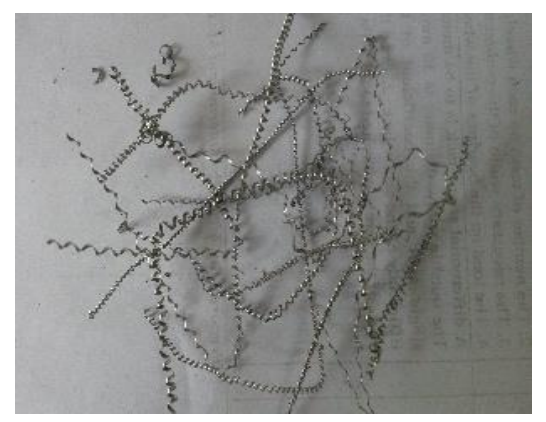

$\mathrm{s}=450 \mathrm{~mm} / \mathrm{min}$, $\mathrm{f}=0.125 \mathrm{~mm} / \mathrm{rev} \& \mathrm{~d}=2 \mathrm{~mm}$

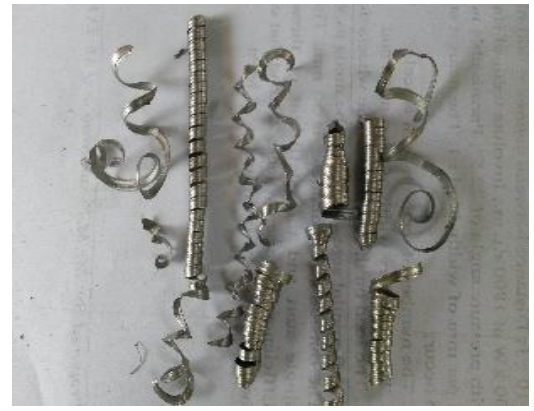

$\mathrm{s}=180 \mathrm{~mm} / \mathrm{min}$, $\mathrm{f}=0.063 \mathrm{~mm} / \mathrm{rev} \& \mathrm{~d}=1 \mathrm{~mm}$

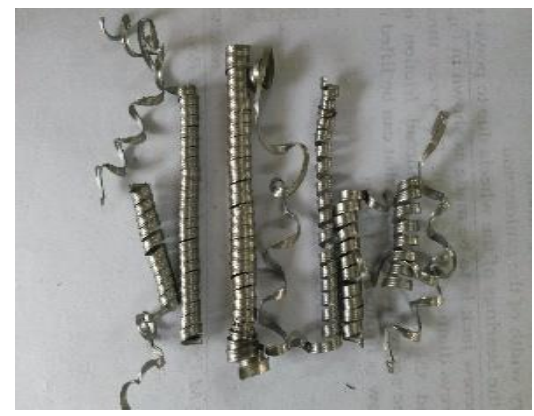

$\mathrm{s}=280 \mathrm{~mm} / \mathrm{min}$, $\mathrm{f}=0.045 \mathrm{~mm} / \mathrm{rev} \& \mathrm{~d}=1.5 \mathrm{~mm}$

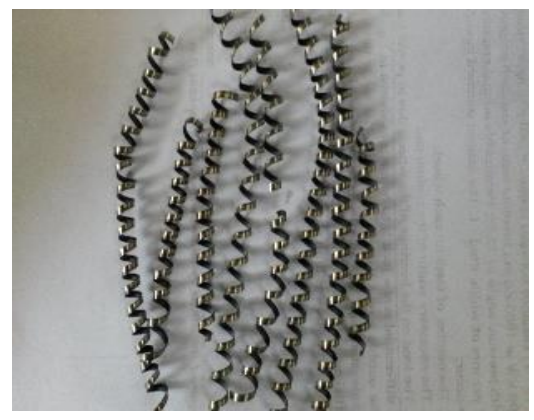

$\mathrm{s}=180 \mathrm{~mm} / \mathrm{min}$, $\mathrm{f}=0.16 \mathrm{~mm} / \mathrm{rev} \& \mathrm{~d}=2 \mathrm{~mm}$

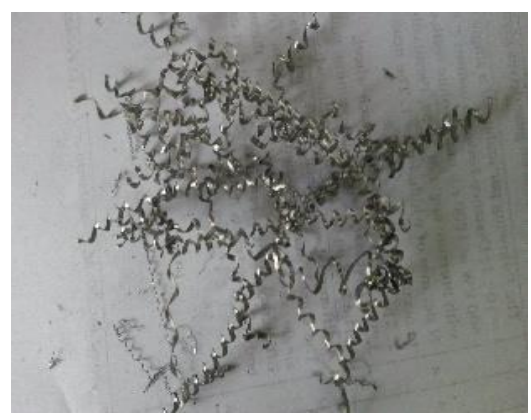

$\mathrm{s}=450 \mathrm{~mm} / \mathrm{min}$, $\mathrm{f}=0.063 \mathrm{~mm} / \mathrm{rev} \& \mathrm{~d}=2.5 \mathrm{~mm}$ 


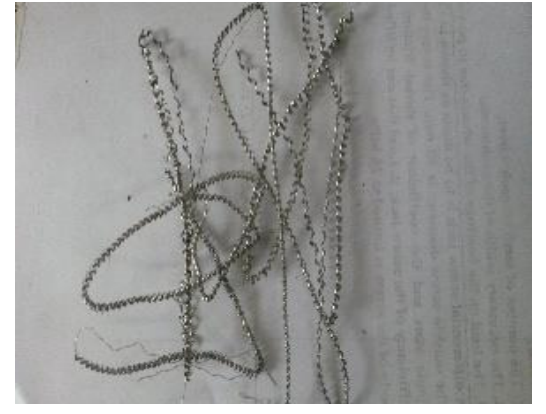

$\mathrm{s}=450 \mathrm{~mm} / \mathrm{min}$, $\mathrm{f}=0.16 \mathrm{~mm} / \mathrm{rev} \& \mathrm{~d}=1 \mathrm{~mm}$

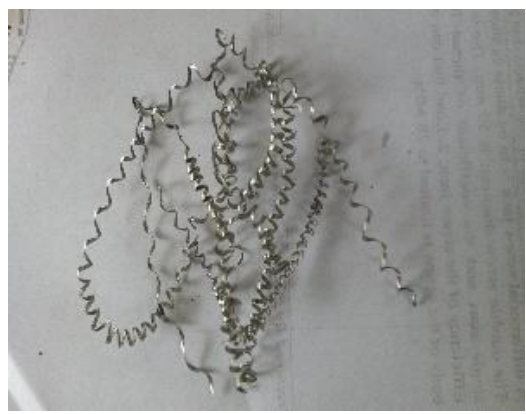

$\mathrm{s}=710 \mathrm{~mm} / \mathrm{min}$, $\mathrm{f}=0.063 \mathrm{~mm} / \mathrm{rev} \& \mathrm{~d}=1 \mathrm{~mm}$

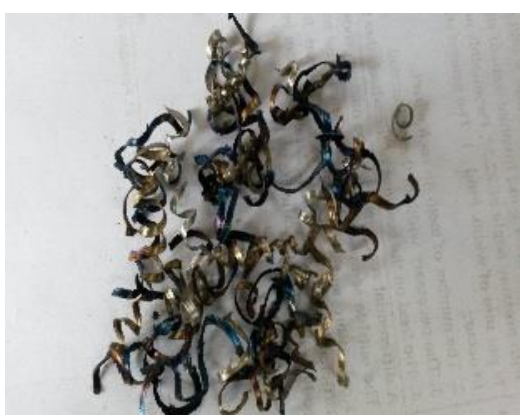

$\mathrm{s}=710 \mathrm{~mm} / \mathrm{min}$, $\mathrm{f}=0.063 \mathrm{~mm} / \mathrm{rev} \& \mathrm{~d}=1 \mathrm{~mm}$

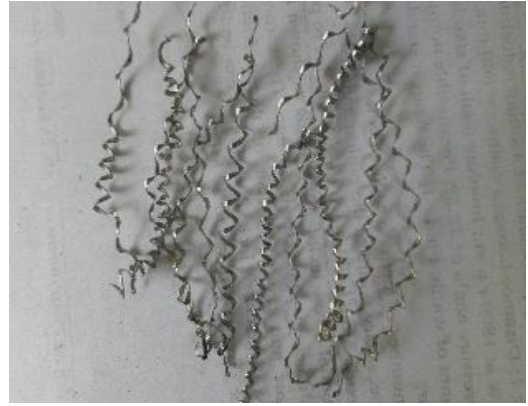

$\mathrm{s}=450 \mathrm{~mm} / \mathrm{min}$, $\mathrm{f}=0.063 \mathrm{~mm} / \mathrm{rev} \& \mathrm{~d}=1 \mathrm{~mm}$

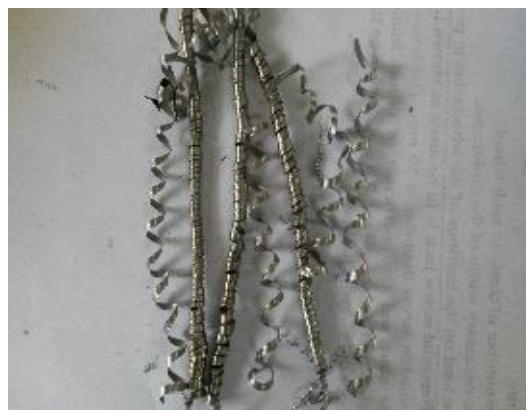

$\mathrm{s}=710 \mathrm{~mm} / \mathrm{min}$ $\mathrm{f}=0.09 \mathrm{~mm} / \mathrm{rev} \& \mathrm{~d}=1.5 \mathrm{~mm}$

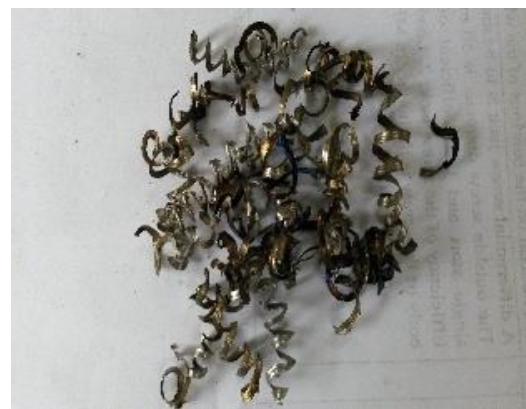

$\mathrm{s}=710 \mathrm{~mm} / \mathrm{min}$ $\mathrm{f}=0.16 \mathrm{~mm} / \mathrm{rev} \& \mathrm{~d}=2.5 \mathrm{~mm}$

Fig. 5. Photographs of various chips formed at different cutting conditions in the machining of AISI 1040 steel using micro-grooved WC cutting tools.

\subsection{S/N Ratios and Analysis of Variance Results for Tool Tip Temperature}

Table 5. S/N ratios for tool tip temperatures.

\begin{tabular}{cccc}
\hline Levels & Cutting speed & Feed & Depth of cut \\
\hline 1 & -30.6615 & -30.6615 & $-30.5397(\mathrm{P})$ \\
2 & -31.231 & -30.8465 & -31.1466 \\
3 & -30.6487 & -31.7233 & -30.9407 \\
4 & -32.5114 & -32.1126 & -32.1437 \\
5 & -32.0031 & -31.6071 & -32.4235 \\
\hline Delta & 1.8627 & 1.4511 & 1.8838 \\
\hline
\end{tabular}


Table 6. ANOVA table for tool tip temperatures.

\begin{tabular}{cccccccc}
\hline Source & DF & Adj.SS & Adj.MS & $\begin{array}{c}\text { F- } \\
\text { value }\end{array}$ & $\begin{array}{c}\text { P- } \\
\text { value }\end{array}$ & \% P & Rank \\
\hline Cutting speed & 4 & 214.5 & 53.615 & 6.20 & 0.002 & $0.395(\mathrm{P})$ & 1 \\
Feed & 4 & 113.9 & 28.48 & 2.04 & 0.129 & 0.210 & 3 \\
Depth of cut & 4 & 213.4 & 53.34 & 6.12 & 0.02 & 0.393 & 2 \\
Error & & & & & & 0.0002 & \\
\hline Total & & 541.8 & & & & 1 & \\
\hline
\end{tabular}

\subsection{S/N Ratios and Analysis of Variance results for Surface Roughness}

Similarly, signal-to-noise ratio values are calculated for surface roughness and the results are presented in Table 6. It shows that the surface roughness is mostly influenced by the cutting speed and its value is about -6.75916. ANOVA results (Table 7) show that the machining variable cutting speed value at level 5 is a preferable one among all for getting minimum surface roughness in the machining of AISI 1040 steel using micro-grooved cutting tools. Figures $6 \& 7$ represents the main effect plots for tool tip temperatures \& surface roughness with respect to all input parameters. ANOVA is done using Minitab 17 statistical software to observe the significant parameters among all the input variables(Cutting speed, feed and depth of cut) on the output variables(Tool tip temperatures and surface roughness). The ANOVA results shown in Figs. 6-7 shows that the high cutting speed, medium feed and depth of cut conditions are suitable for getting low surface roughness values during machining.

Table 7. S/N ratios for surface roughness.

\begin{tabular}{cccc}
\hline Levels & Cutting speed & Feed & Depth of cut \\
\hline 1 & -11.8213 & -13.7506 & -14.1087 \\
2 & -15.0889 & -12.0107 & -13.2363 \\
3 & -14.2782 & -11.3405 & -11.4853 \\
4 & -15.8618 & -16.9679 & -15.0908 \\
5 & $\mathbf{- 6 . 7 5 9 1 6 ( P )}$ & -15.9903 & -14.4156 \\
\hline Delta & 4.04 & 5.6274 & 3.6055 \\
\hline
\end{tabular}

Table 8. ANOVA table for surface roughness.

\begin{tabular}{cccccccc}
\hline Source & DF & Adj.SS & Adj.MS & F-value & P-value & \% P & Rank \\
\hline Cutting speed & 4 & 45.48 & 11.369 & 3.49 & 0.027 & $0.487(\mathrm{P})$ & 1 \\
Feed & 4 & 37.45 & 9.369 & 2.55 & 0.073 & 0.4017 & 2 \\
Depth of cut & 4 & 10.28 & 2.569 & 0.50 & 0.734 & 0.1102 & 3 \\
Error & & & & & 0.0002 & \\
\hline Total & & & & & & \\
\hline
\end{tabular}




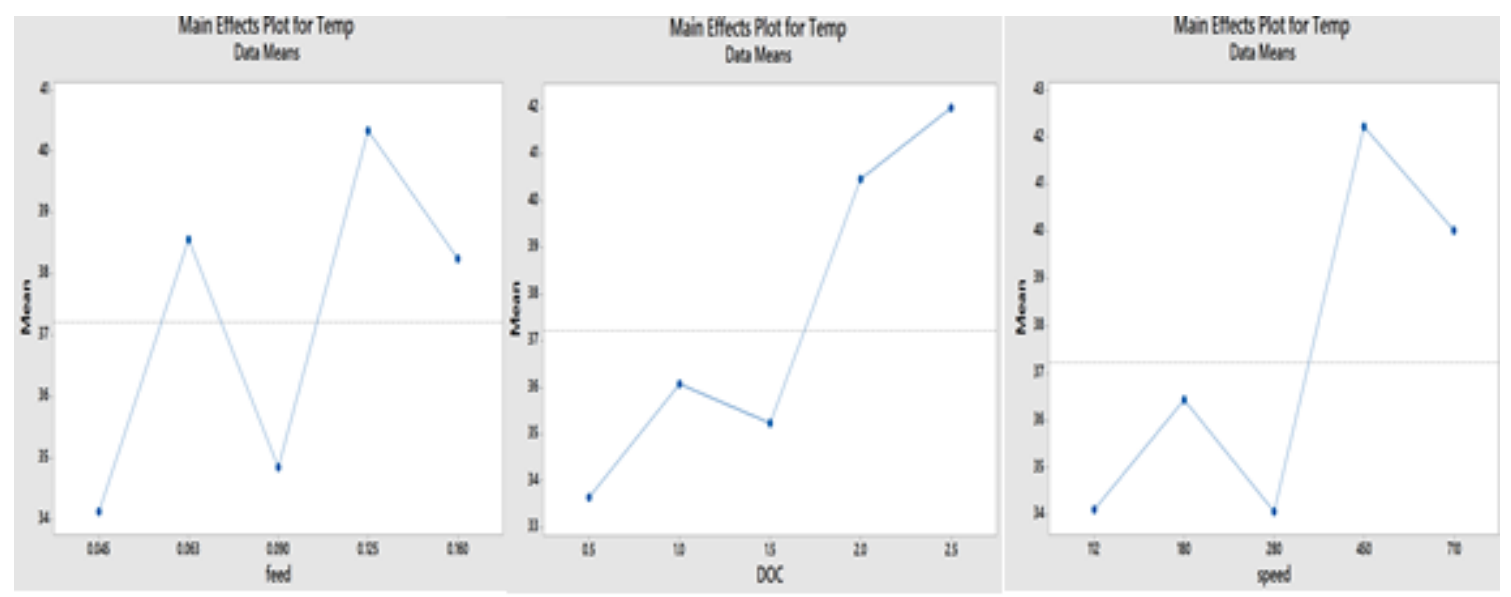

Fig. 6. Main effect plots for tool tip temperature with respect to all input parameters.

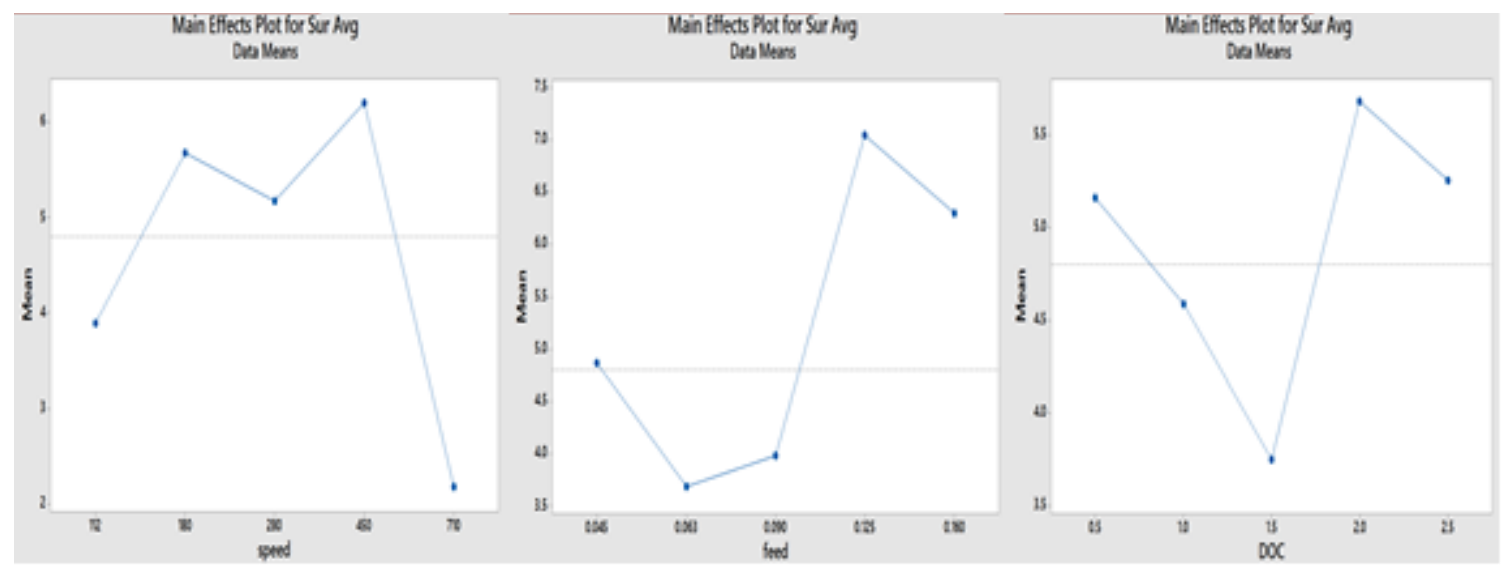

Fig. 7. Main effect plots for surface roughness with respect to all input parameters.

\section{Conclusions}

An investigation has been made on the experimental study and optimization of machining parameters in turning of AISI 1040 steel with micro-grooved WC cutting tools. This is done using calculations of signalto-noise ratios and analysis of variance technique. Some concluding remarks of the present study are given below.

- The electric discharge machine can be used as an alternative to micro-grinding process to cut grooves on the rake face of Tungsten carbide cutting tools. A series of micro-grooves along the cutting edge (i.e. $200-500 \mu \mathrm{m}$ from the side and end cutting edges and $1400 \mu \mathrm{m}$ from nose) are machined on the tool rake surface.

- A Taguchi orthogonal array is used to set the possible combinations of all input parameters. Later these combinations are categorized into three groups (low, medium and high machining conditions).

- Taguchi design of experiments has given satisfactory results by reducing the number of experiments with the L32 orthogonal array. It is also helpful in reducing the total number of experiments from 32 to 24.

- Dry turning tests of AISI 1040 steel under each group enables to assess the performance of microgrooved WC cutting tools. The micro-grooved WC tool has strong chip breakable capacity, tool wear, chip size and cutting sparks.

- From the one way ANOVA \& Signal-to-noise ratio results it has identified that the cutting speed is the most influencing parameter at the following levels.

$\checkmark$ Tool tip temperature at level 1(i.e. $112 \mathrm{~m} / \mathrm{min}$ ). 
$\checkmark$ Surface roughness at level 5(i.e. $720 \mathrm{~m} / \mathrm{min}$ ).

- The present work can be extended to characterization of the tool wear (i.e. Crater wear and edge chipping) and the most influencing parameters can also be identified.

\section{Acknowledgement}

Authors are thankful to the Department of Science and Technology, Government of India for the financial support that made this research possible. The authors also acknowledge GMR Institute of Technology, Rajam, India for providing technical facilities and assistance.

\section{References}

[1] G. Amitabh and M. A. Kumar, Manufacturing Science. New Delhi: East West Press, 1985.

[2] V. P. Astakov, S. V. Shvets, and M. O. M. Osman, "Chip structure classification based on mechanics of its formation," Journal of Materials Process Technology, vol. 71, pp. 247-257, 1997.

[3] M. Neslušan, M. Šípek, and J. Mrázik, "Analysis of chip formation during hard turning through acoustic emission," Materials Engineering-Materiálové in žinierstvo, vol. 19, no. 1, pp. 1-11, 2011.

[4] G. Sutter, L. Faure, A. Molinari, A. Delime, and D. Dudzinski, "Experimental analysis of the cutting process and chip formation at high speed machining," Journal de Physique IV Colloque, vol. 07, no. C3, pp. 33-38, 1997.

[5] K. K. Singh, M. joshi, A. Bahuguna, and R. Pant, "Effect of rake angles and material properties on chip formation: A review," International Journal of Engineering Science and Innovative Technology (IJESIT), vol. 3, no. 6, pp. 526-530, 2014.

[6] K. S. Kumar and J. S. Senthilkumaar, "Analysis of flank wear and chip morphology when machining super duplex stainless steel in a gas cooled environment," International Journal of Engineering and Technology (IJET), vol. 5, no. 6, pp. 5045-5056, 2014.

[7] J. Xie, M.-J. Luo, J.-L. He, X.-R. Liu, and T.-W. Tan, "Micro-grinding of micro-groove array on tool rake surface for dry cutting of titanium alloy," International Journal of Precision Engineering and Manufacturing, vol. 13, no. 10, pp. 1845-1852, 2012.

[8] B Kumaragurubaran, P Gopal, T Senthil Kumar, M Prasanna Mugunthan, and N H Mohamed Ibrahim, "Optimization of turning parameters of EN-9 steel using design of experiments", International Journal of Mechanical Engineering Research and Robotics, vol. 2, no. 3, pp.182-190, 2013.

[9] S. Dewangan, S. Gangopadhyay, C. K. Biswas, "Multi-response optimization of surface integrity characteristics of EDM process using grey-fuzzy logic-based hybrid approach," Engineering Science and Technology, An International Journal, vol. 18, no. 3, pp. 361-368, 2015.

[10] M. Dastagiri and A. Hemantha Kumar, "Experimental investigation of EDM parameters on stainless steel \& En41b," Procedia Engineering, vol. 97, pp. 1551-1564, 2014.

[11] Vikasa, Shashikant, A. K. Roy, and K. Kumar "Effect and optimization of machine process parameters on MRR for EN19 \& EN41 materials using Taguchi," Procedia Technology, vol. 14, pp. 204210, 2014.

[12] S. Backer, C. Mathew, and S. K. George, "Optimization of MRR and TWR on EDM by using Taguchi's method and ANOVA," International Journal of Innovative Research in Advanced Engineering (IJIRAE), vol. 1, no. 8, pp. 106-112,

[13] S. S. Habib, "Study of the parameters in electrical discharge machining through response surface methodology approach," Applied Mathematical Modelling, vol. 33, no. 12, pp. 4397-4407, 2009.

[14] C. L. V. R. S. V. Prasad, S. V. Ramana, S. Srikiran, and K. Ramji, "Experimental investigations for characterization and analysis of rake face of the WC-Co inserts using Taguchi method," in Proc. ASME 2010 International Mechanical Engineering Congress and Exposition, Vol. 3: Design and Manufacturing, Parts A and B, Vancouver, British Columbia, Canada, November 12-18, 2010, pp. 1055-1063.

[15] P. N. L. Pavani, C. L. V. R. S. V. Prasad, S. V. Ramana, and K. Ramji, "The influence of array of alternative nanocoatings on the characterization of wear zones on the rake face of tungsten carbide cutting tools," presented at International Conference on PRECISION, MESO, MICRO, AND NANO ENGINEERING (COPEN-8).

[16] P. N. L. Pavani, C. L. V. R. S. V. Prasad, K. Ramji, and S. V. Ramana, "Characterization of wear and prediction of wear zone locations on the rake face using Mamdani fuzzy inference system," in 
Proceedings of the Institution of Mechanical Engineers, Part B: Journal of Engineering Manufacture, January 27, 2016, p.0954405415624632. doi:10.1177/0954405415624632.

[17] G. M. Robinson, M. J. Jackson, and M. D. Whitfield, "A review of machining theory and tool wear with a view to developing micro and nano machining processes," Journal of Materials Science, vol. 42, no. 6, pp. 2002-2015, 2007.

[18] M. Venkata Ramana, G. Krishna Mohan Rao, and D. Hanumantha Rao, "Optimization and effect of process parameters on tool wear in turning of titanium alloy under different machining conditions," International Journal of Materials, Mechanics and Manufacturing, vol. 2, no. 4, pp. 272-277, 2014.

[19] E. Yahya, G. F. Ding, and S. F. Qin, "Optimization of machining parameters based on surface roughness prediction for AA6061 using response surface method," American Journal of Science and Technology, vol. 2, no. 5, pp. 220-231, 2015.

[20] M. Y. Noordin, V. C. Venkatesh, S. Sharif, S. Elting, and A. Abdullah, "Application of response surface methodology in describing the performance of coated carbide tools when turning AISI 1045 steel," Journal of Materials Processing Technology, vol. 145, no. 1, pp. 46-58, 2014.

[21] W. H. Yang and Y. S. Tarng, "Design optimization of cutting parameters for turning operations based on the Taguchi method," Joumal of Materials Processing Technology, vol. 84, no. 1-3, pp. 122-129, 1998.

[22] P. Sahoo, "Optimization of turning parameters for Surface roughness using RSM and GA," Advances in Production Engineering \& Management, vol. 6, no. 3, pp. 197-208, 2011.

[23] M. M. Uddin and S. S. Hossain, "Optimization of tool wear for different metals in turning operation using ANOVA \& regression analysis," International Journal of Science, Engineering and Technology Research (IJSETR), vol. 4, no. 7, pp. 2533-2545, 2015. 